\title{
Attachment and Proliferation of Osteoblasts on Lithium-Hydroxyapatite Composites
}

\author{
Ana Paula M. Shainberg, ${ }^{1}$ Patrícia Valério, ${ }^{2}$ Alessandra Zonari, ${ }^{2}$ Faik N. Oktar, $, 4,5$ \\ Lutfiye S. Ozyegin, ${ }^{6}$ Manuel Pedro F. Graça, ${ }^{7}$ Maria F. Leite, ${ }^{8}$ and Alfredo M. Goes ${ }^{1,2}$ \\ ${ }^{1}$ Department of Morphology, Federal University of Minas Gerais, 31270-901 Belo Horizonte, MG, Brazil \\ ${ }^{2}$ Department of Biochemistry and Immunology, Federal University of Minas Gerais, 31270-901 Belo Horizonte, MG, Brazil \\ ${ }^{3}$ Department of Bioengineering, Faculty of Engineering, Marmara University, Goztepe Campus, Kadikoy, 34722 Istanbul, Turkey \\ ${ }^{4}$ Department of Medical Imaging Techniques, School of Health Related Professions, Marmara University, Haydarpasa Campus, \\ Uskudar, 34668 Istanbul, Turkey \\ ${ }^{5}$ Nanotechnology and Biomaterials Application and Research Centre, Marmara University, Goztepe Campus, Kadikoy, \\ 34722 Istanbul, Turkey \\ ${ }^{6}$ Marmara University, Goztepe Campus, Kadikoy, 34722 Istanbul, Turkey \\ ${ }^{7}$ I3N-Aveiro-Physic Department, University of Aveiro, 3810-193 Aveiro, Portugal \\ ${ }^{8}$ Department of Physiology and Biophysics, Federal University of Minas Gerais, 31270-901 Belo Horizonte, MG, Brazil
}

Correspondence should be addressed to Alfredo M. Goes, alfredomgoes@gmail.com

Received 7 November 2011; Accepted 2 February 2012

Academic Editor: Jinlong Yang

Copyright (C) 2012 Ana Paula M. Shainberg et al. This is an open access article distributed under the Creative Commons Attribution License, which permits unrestricted use, distribution, and reproduction in any medium, provided the original work is properly cited.

The biocompatibility and bioactivity properties of hydroxyapatites (HAs) modified through lithium addition were investigated. Hydroxyapatites obtained from bovine bone were mixed with lithium carbonate ( $\mathrm{Li}$ ), in the proportions of $0.25,0.50,1.00$, and $2.00 \% \mathrm{wt}$, and sintered at $900^{\circ}, 1000^{\circ}, 1100^{\circ}, 1200^{\circ}$, and $1300^{\circ} \mathrm{C}$, creating LiHA samples. The osteoblast culture behavior was assessed in the presence of these LiHA compositions. The cellular interactions were analyzed by evaluating the viability and cellular proliferation, ALP production and collagen secretion. The cytotoxic potential was investigated through measurement of apoptosis and necrosis induction. The process of cellular attachment in the presence of the product of dissolution of LiHA, was evaluated trough fluorescence analysis. The physical characteristics of these materials and their cellular interactions were examined with SEM and EDS. The results of this study indicate that the LiHA ceramics are biocompatible and have variable bioactivities, which can be tailored by different combinations of the concentration of lithium carbonate and the sintering temperature. Our findings suggest that LiHA $0.25 \% \mathrm{wt}$, sintered at $1300^{\circ} \mathrm{C}$, combines the necessary physical and structural qualities with favorable biocompatibility characteristics, achieving a bioactivity that seems to be adequate for use as a bone implant material.

\section{Introduction}

Bones provide mechanical protection for internal organs and the blood-forming marrow, and they facilitate locomotion and serve as a reservoir for calcium, magnesium, and phosphate minerals [1]. Bones are formed by a series of complex events involving mineralization with calcium phosphate in the form of hydroxyapatite (HA) on extracellular matrix proteins primarily consisting of collagen type I. HA is one of the most attractive materials for human hard tissue implants because of its close resemblance to bones and teeth [2]. Bone fractures and related damages result in more than 1.3 million surgical procedures every year in the United States [3]. In many cases, such as with acute and chronic injuries or defects, a bone graft substitute is necessary. Current options include autografts, allografts, and an assortment of synthetic or biomimetic materials and devices. Each of these options has significant limitations, such as the need for a second site of surgery, a limited resource supply, an inadequate size and shape, and morbidity associated with the donor site. Thus there remains a need for new options [4]. Calcium phosphate (Ca-P) biomaterials are a good option for use as grafts for 
bone repair, augmentation, or substitution. Ca-P materials differ in origin, composition, physical form, and physicochemical properties, while offering similar compositions to bone mineral phases, bioactivity, promotion of cellular functions, and osteoconductivity [5]. However, despite its excellent biocompatibility, the application of Ca-P in the form of $\mathrm{HA}$ is limited to non-load-bearing implants because of its poor mechanical properties [4]. Significant enhancements in strength and toughness of HA have been achieved by making composite materials using various types of second phases, such as lithium (Li) [6, 7]. Fanovich et al. [8] and Oktar et al. [9] have determined that lithium addition forms a liquid phase which improves the sintering process. It has also been demonstrated that Li causes a decrease in the solubility of HA $[10,11]$ and that solubility is directly related to biocompatibility [12]. Lithium is a bioelectric material, and studies concerning the biocompatibility of this type of material are very rare [8]. Natural bone manifests a particular electrical pattern which is believed to have an important influence on the architecture, composition, and physiology of living osteoblasts [13]. It has been stated that the electromagnetic field is important to bone healing [14-16]. In this study, our aim was to investigate the biocompatibility of different LiHA compositions using primary cultures of osteoblasts.

\section{Methods}

2.1. Preparation of LiHA Samples. BHA (bone hydroxyapatite) powder was derived from bovine bone with a calcination method at $850^{\circ} \mathrm{C}$, as described in a previous study [9]. After grinding, the BHA powder was mixed with $0.25,0.50$, 1.00 , and $2.00 \mathrm{wt} \%$ of fine $\mathrm{Li}_{2} \mathrm{CO}_{3}$ powder. The mixtures were homogenized by ball milling and then pressed to form cylindrical compacted pellets, according to the British standard no. 7253. The pellets were sintered in an open atmospheric furnace at $900^{\circ} \mathrm{C}, 1000^{\circ} \mathrm{C}, 1100^{\circ} \mathrm{C}, 1200^{\circ} \mathrm{C}$, and $1300^{\circ} \mathrm{C}$ for 4 hours (Nabertherm HT 16/17, Lilienthal, Germany). Compression strength tests were carried out on the sintered samples with a universal testing machine (DVT.e Devotrans Inc. Istanbul, Turkey; speed $2 \mathrm{~mm} / \mathrm{min}$ ). Density (by the Archimedes method) and microhardness (TUKON, Wilson Instruments, Group of Instron, Darmstadt, Germany; $200 \mathrm{~g}$ load) were also measured. The microstructure was observed by SEM (Jeol JSM-840, Tokyo, Japan) on the polished surface after etching with $0.1 \mathrm{M}$ lactic acid for 10 seconds. X-ray diffraction analysis (XRD, D8 Advance, Bruker-AXS, Germany) was also conducted.

2.2. Culture of Osteoblasts. Osteoblasts were isolated from the calvaria of 1-to 5-day-old neonatal Wistar rats [17]. The calvaria were dissected and freed from soft tissue, cut into small pieces, and rinsed in sterile phosphate-buffered saline without calcium and magnesium. The calvaria pieces were incubated with $1 \%$ trypsin-EDTA (GIBCO) for $5 \mathrm{~min}$, followed by four sequential incubations with $2 \%$ collagenase (GIBCO) at $37^{\circ} \mathrm{C}$ for $45 \mathrm{~min}$ each. The supernatant of the first collagenase incubation, which contains a high proportion of periosteal fibroblasts, was discarded. The other digestions produced a suspension of cells with a high proportion of osteoblasts. After centrifugation at $1000 \mathrm{~g}$ for $5 \mathrm{~min}$, each pellet was suspended in $5 \mathrm{~mL}$ of RPMI (GIBCO) medium supplemented with $10 \%$ FBS, $1 \%$ antibioticantimycotic. The cells were seeded into $25 \mathrm{~mL}$ tissue culture flasks and maintained in a controlled 5\% $\mathrm{CO}_{2}, 95 \%$ humidified incubator at $37^{\circ} \mathrm{C}$. After confluence was achieved, the cells from the second passage were used for experiments.

\subsection{Preparation of the Ionic Products from the Dissolution} of the Bioceramics. Bioceramics were suspended in culture medium RPMI (GIBCO), $0.5 \mathrm{~g}$ in $50 \mathrm{~mL}$, shaked for $5 \mathrm{~h}$ at $37^{\circ} \mathrm{C}$ and filtered twice. The second filtration was conducted in a $0.22 \mathrm{~mm}$ filter for sterilization. This medium, containing ionic products from the bioceramics dissolution which had the $\mathrm{pH}$ adjusted to 7.0 , was supplemented with $10 \%$ of FBS (GIBCO) and $1 \%$ antibiotic-antimycotic and was used to stimulate the osteoblasts.

\subsection{Stimulation of Osteoblasts with Ionic Products from the} Dissolution of the Samples. Osteoblasts were plated in 24 well plates at a density of $5 \times 10^{4}$ cells $/ \mathrm{mL}$, and after $72 \mathrm{~h}$, the medium was changed to medium containing ionic products from the dissolution of the samples. After $72 \mathrm{~h}$ of incubation, osteoblasts were tested. Control cells were submitted to the same process using only medium, without ionic products.

2.5. Stimulation of Osteoblasts by LiHA Powders. Osteoblasts were seeded in 24 well plates at a density of $5 \times 10^{4}$ cells $/ \mathrm{mL}$ with medium containing each type of LiHA powder. After adhesion, the LiHA powders were placed in the cell cultures at a rate of 10 cells/1 particle. Control cells were osteoblasts in pure medium.

2.6. Viability Assay. The viability of the cells in culture with medium containing each type of LiHA powder was evaluated by the 3-(4,5-dimethylthiazol-2-yl)-2,5-diphenyl tetrazolium bromide (MTT) assay. Briefly, MTT $(5 \mathrm{mg} / \mathrm{mL})$ was added to each well. The culture was then incubated in a humidified $5 \% \mathrm{CO}_{2}$ incubator at $37^{\circ} \mathrm{C}$. Two hours later, the cell morphology and formazan salts were visualized by inverted optical microscopy. The formazan salts were dissolved with $10 \%$ SDS-HCl overnight, and the optical density measurement was conducted at $595 \mathrm{~nm}$. The values of all samples were calculated relative to the value of the control and expressed as percentages. The control consisted of nonstimulated cells.

2.7. Alkaline Phosphatase Activity. Alkaline phosphatase production by the cells cultured with medium containing each type of LiHA powder was evaluated after $72 \mathrm{~h}$ by BCIP-NBT assay (GIBCO). Briefly, the BCIP-NBT solution was prepared per manufacturer's protocol. The supernatant of each well was removed and placed in a tube. Next, $300 \mu \mathrm{L}$ of each supernatant was mixed with $100 \mu \mathrm{L}$ of BCIP-NBT solution. Simultaneously, $200 \mu \mathrm{L}$ of BCIP-NBT solution was added to each of the wells containing the cell cultures. After $2 \mathrm{~h}$ of incubation in a humidified $5 \% \mathrm{CO}_{2}$ incubator at $37^{\circ} \mathrm{C}$, 


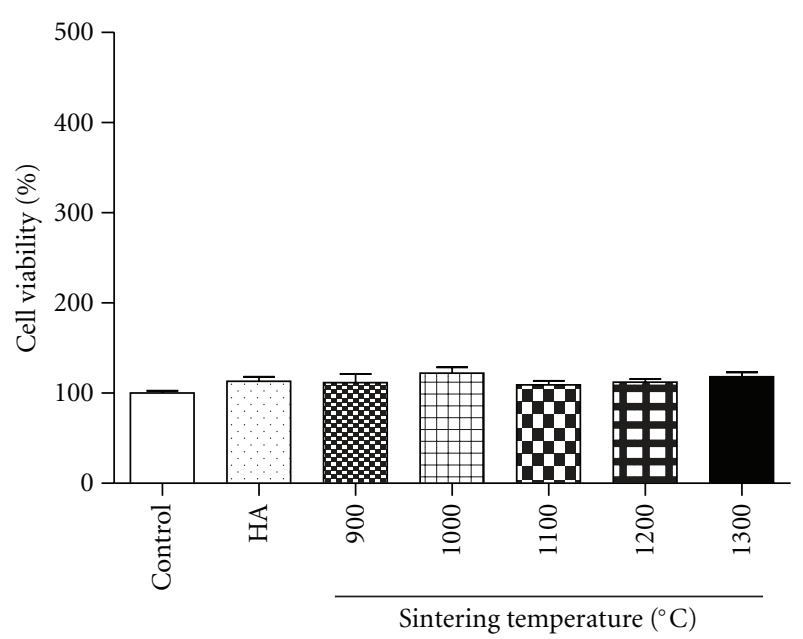

(a)

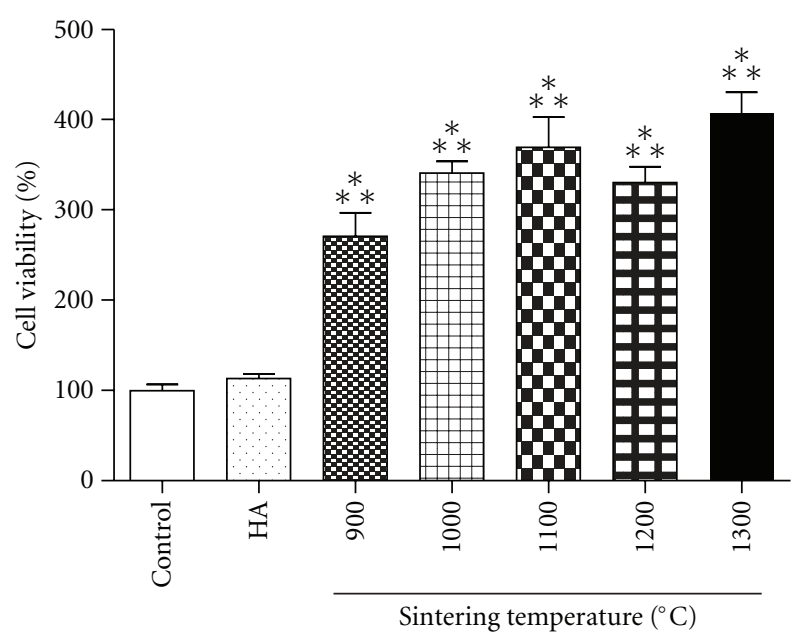

(c)

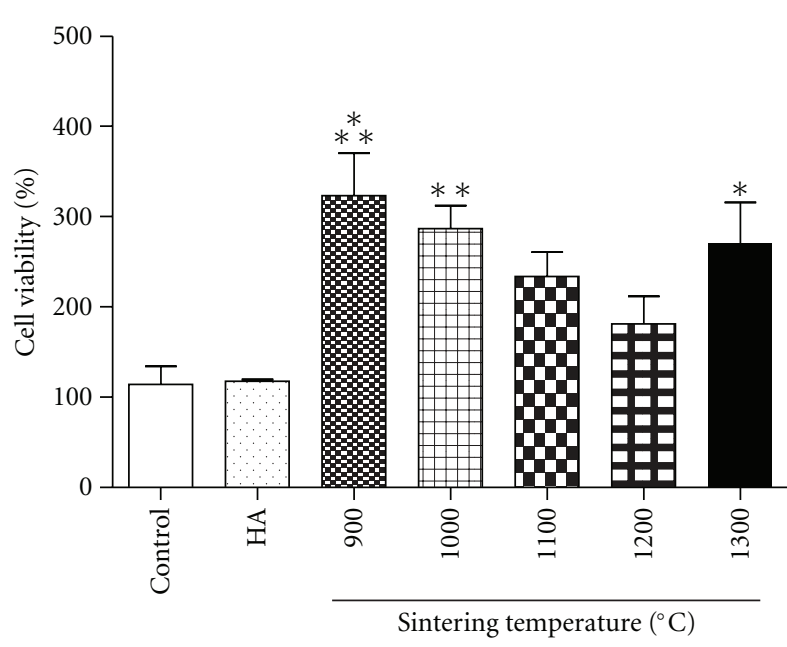

(b)

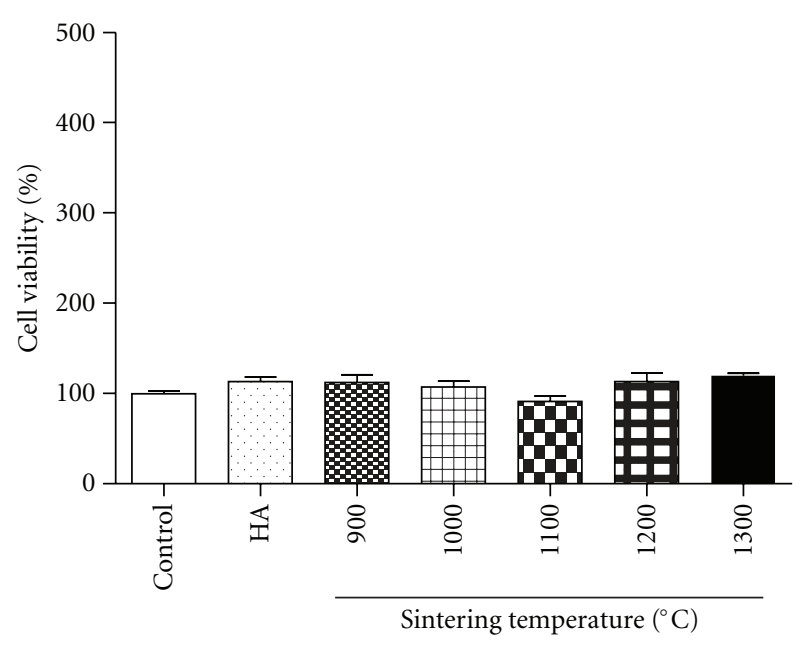

(d)

FIgURE 1: Cellular viability of osteoblasts cultured in the presence of different concentrations of LiHA. (a) $0.25 \% \mathrm{LiHA}$, (b) 0.50\% LiHA, (c) $1.0 \% \mathrm{LiHA}$, and (d) $2.0 \% \mathrm{LiHA}$. The results are expressed as the means $\pm \mathrm{SD},\left({ }^{*}\right)$ indicating a significant difference comparing to control with $P<0.05$.

$100 \mu \mathrm{L}$ of each tube containing the supernatant/BCIP-NBT mixture was transferred to a 96-well plate, and the optical density measurement was read at $595 \mathrm{~nm}$. The cells were observed by optical microscopy, and the insoluble purple precipitates were solubilized with $210 \mu \mathrm{L}$ of $10 \%$ SDS-HCl overnight at $37^{\circ} \mathrm{C}$. The alkaline phosphatase production was determined by comparing the optical densities of both cultures with the value of the control and expressed as percentages. The control consisted of nonstimulated cells.

2.8. Collagen Secretion Measurement. Collagen production by the cells cultured in the presence of LiHA samples was evaluated by using a SIRCOL Collagen Assay (Biocolor Ltda, Ireland), according to the manufacturer's instructions. Briefly, the collagen present in the supernatant, precipitated by the dye Sirius red, was solubilized and measured by an optical density analysis at $595 \mathrm{~nm}$. The amount of collagen was calculated based on a standard curve of previously known concentrations of collagen and their optical density measurements. We used cultures without samples as controls. The experiment was performed in triplicate, and data are presented as the mean \pm standard deviations (SD).

2.9. Apoptotic Analysis. The apoptotic parameters were analyzed by flow cytometry using a BD LSR II flow cytometer, and data were analyzed using BD FACSDiva software (Becton Dickinson, San Jose, CA). The samples were analyzed, and in all cases $1 \times 10^{4}$ cells were recorded. Fluorophores were diluted in $\mathrm{Me}_{2} \mathrm{SO}$ or dimethylformamide (DMF), preloaded just prior to FACS analysis, and incubated at $37^{\circ} \mathrm{C}$ and $5 \%$ $\mathrm{CO}_{2}$ in cell culture medium, unless otherwise indicated. Control cells were incubated with vehicles, which never exceeded $0.1 \%$ in the final concentration. Propidium iodide (PI) was added at a final concentration of $10 \mu \mathrm{g} / \mathrm{mL}$ just prior to FACS and analyzed for FL-2 (488 excitation, 575/26 emission). Sequential analysis of the distinct fluorophores 


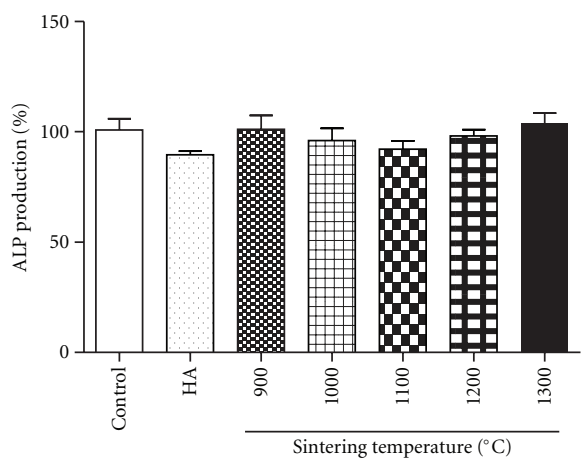

(a)
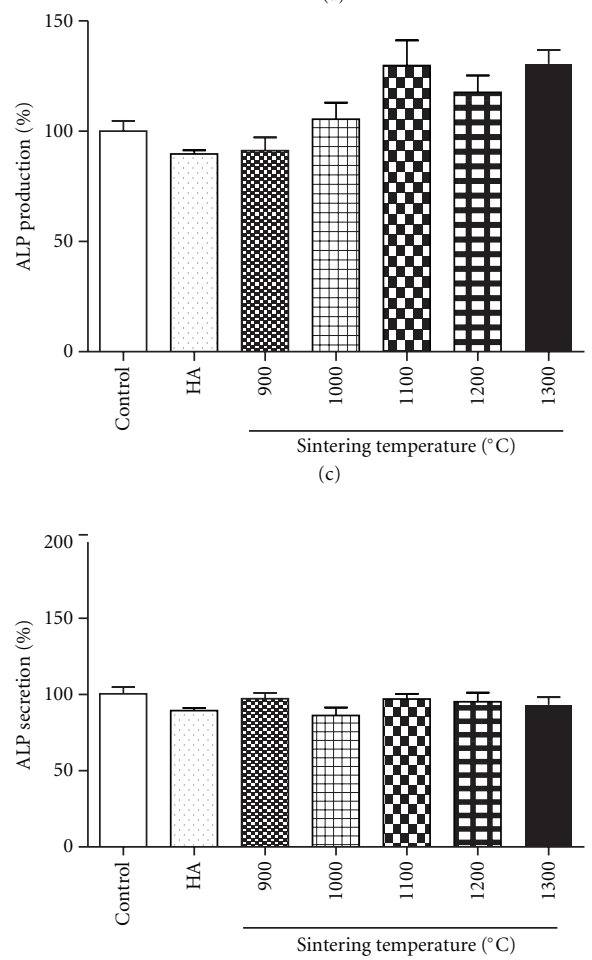

(a)

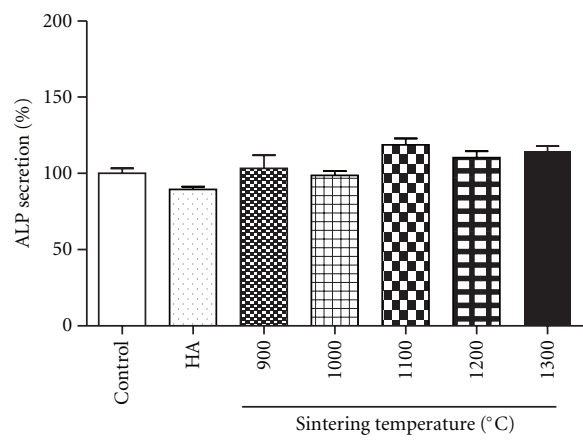

(c)

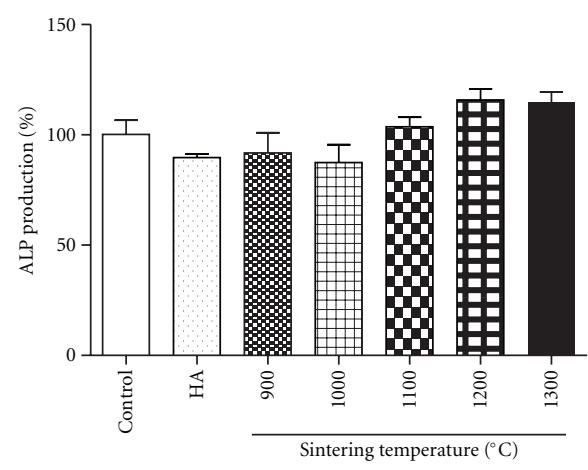

(b)

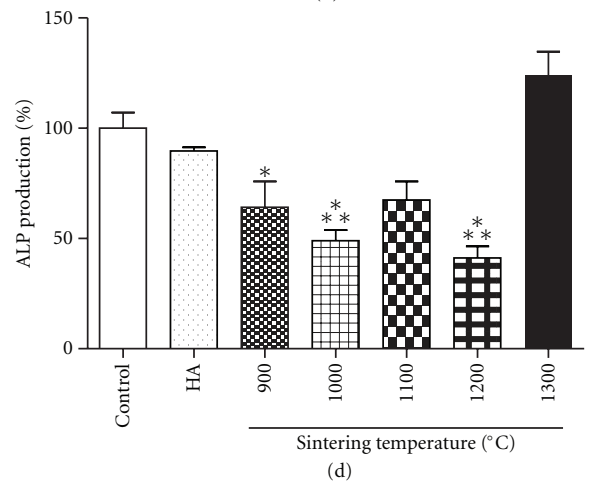

(A)

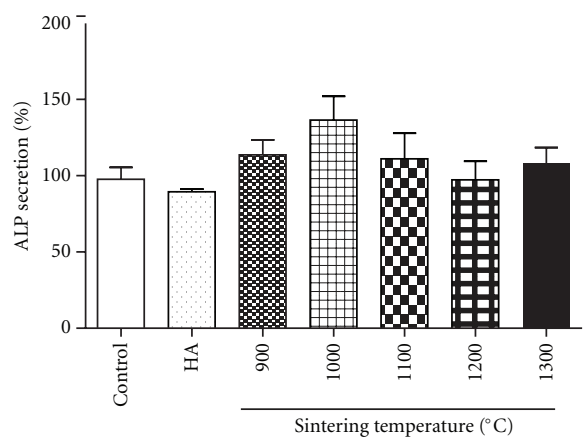

(b)

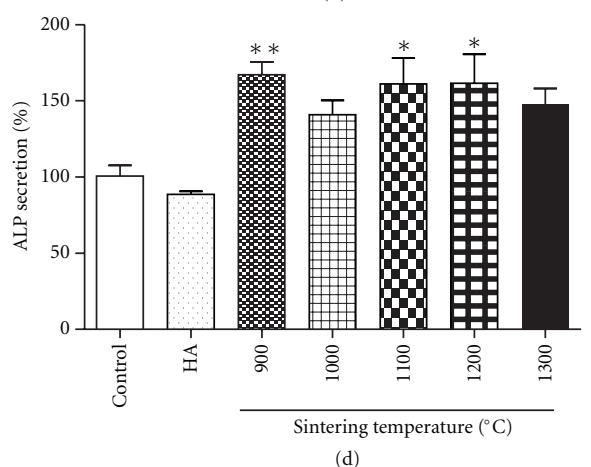

FIgURE 2: Alkaline Phosphatase (ALP) production of osteoblasts cultured in the presence of different concentrations of LiHA. Panel (A): ALP production measured inside the cells. (a) $0.25 \%$ LiHA, (b) $0.50 \%$ LiHA, (c) $1.0 \%$ LiHA, and (d) 2.0\% LiHA. Panel (B): ALP secretion measured from culture supernatant. (a) $0.25 \% \mathrm{LiHA}$, (b) $0.50 \% \mathrm{LiHA}$, (c) $1.0 \% \mathrm{LiHA}$, and (d) $2.0 \% \mathrm{LiHA}$. The results are expressed as the means $\pm \mathrm{SD},\left({ }^{*}\right)$ indicating a significant difference comparing to control with $P<0.05$. 


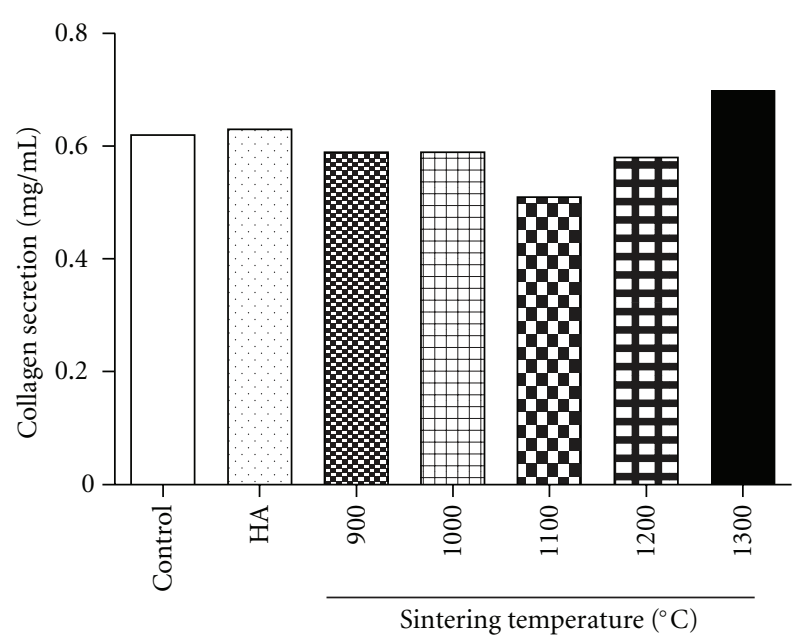

(a)

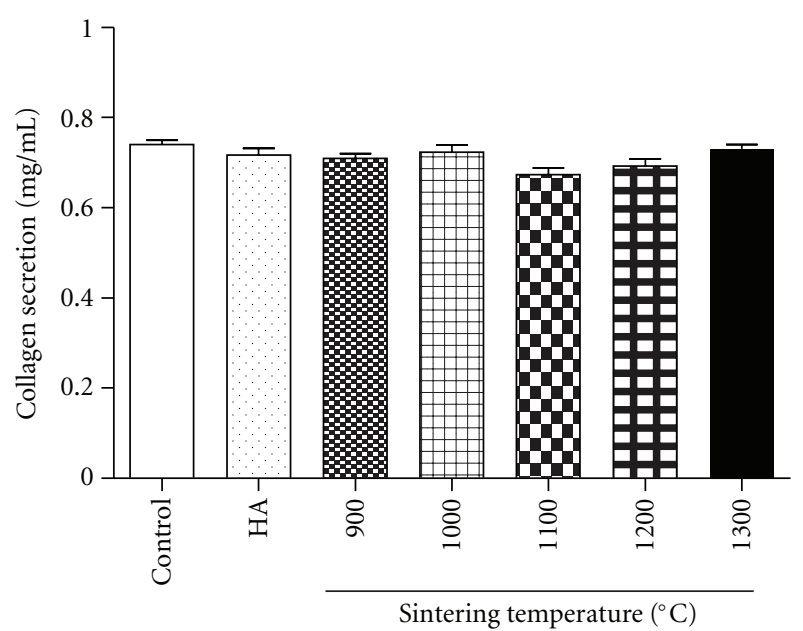

(c)

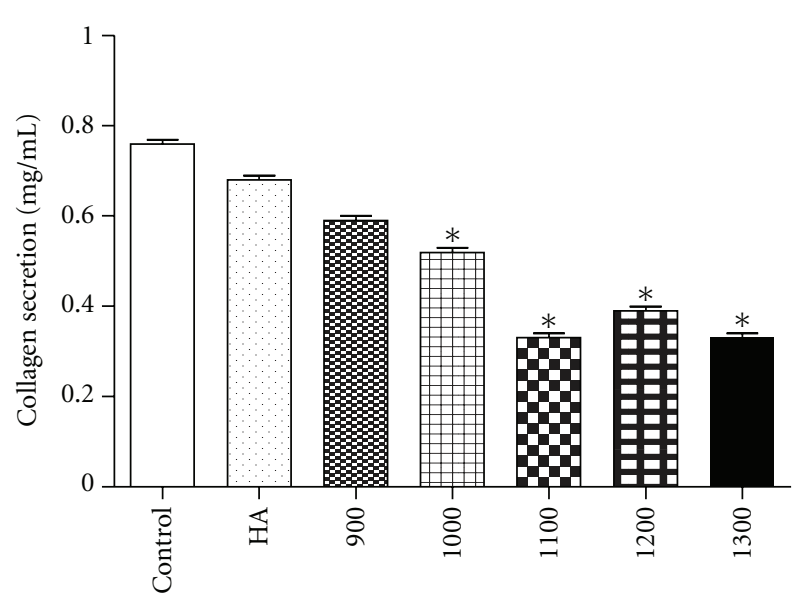

(b)

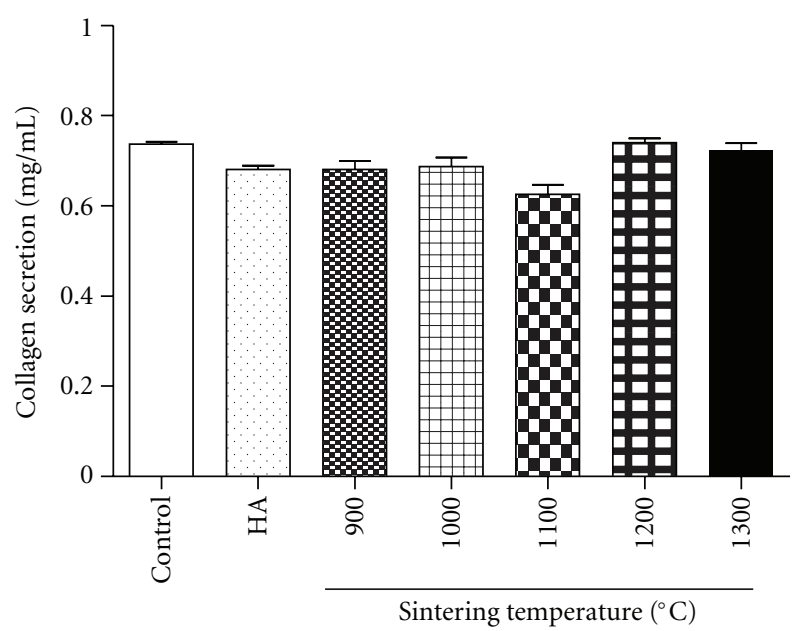

(d)

FIgURE 3: Collagen secretion of osteoblasts cultured in the presence of different concentrations of LiHA. (a) 0.25\% LiHA, (b) 0.50\% LiHA, (c) $1.0 \% \mathrm{LiHA}$, and (d) $2.0 \% \mathrm{LiHA}$. The results are expressed as the means $\pm \mathrm{SD},\left(^{*}\right)$ indicating a significant difference comparing to control with $P<0.05$.

was conducted, and cells with increased PI fluorescence (loss of membrane integrity) were excluded during the analysis. Cell debris or fragments were gated out from the analysis on a forward scatter/side scatter plot. Briefly, gates were set on dot plots of the respective dyefluorescence versus forward scatter and then represented accordingly. Changes in the biochemical parameters during apoptosis were observed as changes in the normal distribution of the population of cells with differences in the mean fluorescence intensity for the distinct reporters for which fluorescence had been used, compared with control cells in the absence of stimulation.

2.10. Immunofluorescence Staining. Confocal microscopy (Zeiss LSM 510 Meta) was used to characterize focal adhesion and cytoskeleton structure of control cells and cells incubated in the presence of the ionic product from the dissolution of each sample. Cells were seeded on glass cover slips, fixed with $3.7 \%$ formalin for $20 \mathrm{~min}$, permeabilized with $0.5 \%$ Triton X-100 in PBS for $30 \mathrm{~min}$, and incubated with the following antibodies in sequence: (1) primary antibodies: mouse monoclonal antibodies against rat vinculin (Abcam-USA, ab11194) diluted 1:400 with PBS containing $1 \%$ BSA, or with rabbit antibodies against rat actin (AbcanUSA, ab1801), diluted $1: 100$ with PBS containing $1 \%$ BSA; (2) secondary antibodies: goat antibodies against mouse IgG labeled with Alexa Fluor 594 (Molecular Probes), diluted 1:600 with PBS containing 1\% BSA, or goat antibodies against rabbit IgG labeled with FITC (Abcam-USA, ab6717), diluted 1:500 with PBS containing 1\% BSA. Then, the samples were incubated with DAPI (Sigma) diluted $1: 10000$ with PBS for nucleus staining.

2.11. Scanning Electron Microscopy (SEM). The LiHA samples with osteoblasts were fixed with a solution containing $2.5 \%$ glutaraldehyde and $0.5 \%$ paraformaldehyde in phosphate buffer ( $\mathrm{pH} 7.4$ ) for 2 hours, postfixed in $1 \%$ osmium 


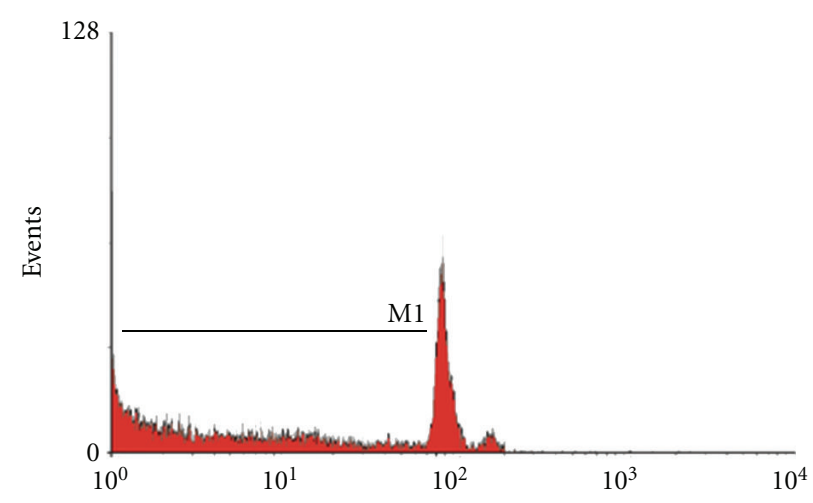

(a)

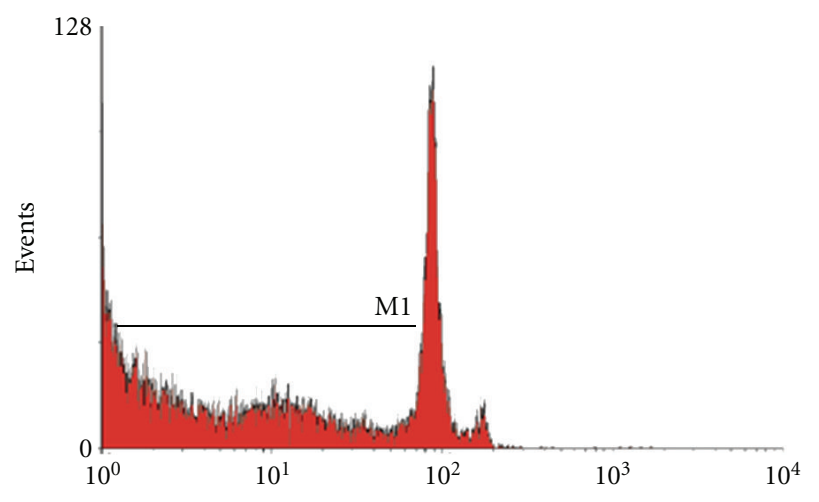

(c)

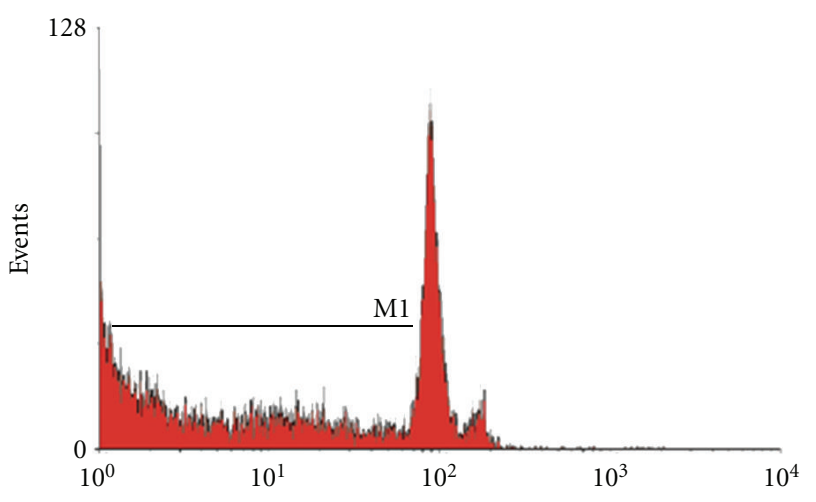

(b)

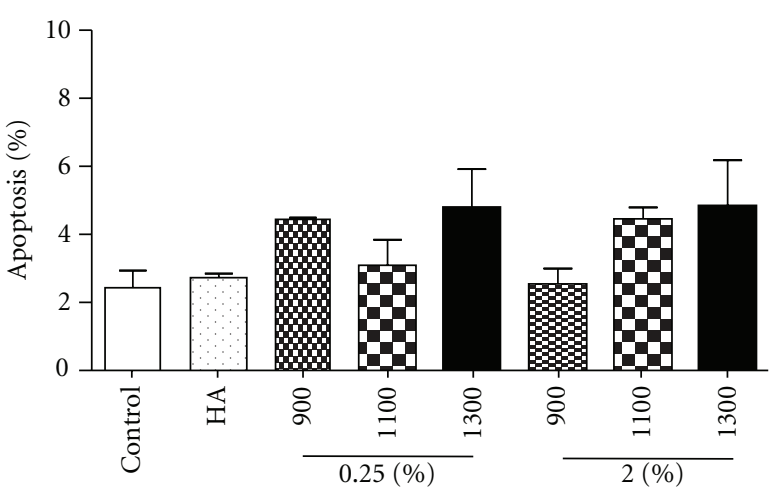

(d)

FIGURE 4: Flow cytometry analysis of apoptotic cells. (a-c) Representative histograms, the M1 marker represents the subdiploid content. (a) Control, (b) Commercial hydroxyapatite, and (c) LiHA sample. (d) Graphic summarizing the percentage of death cells. The results are expressed as the means \pm SD.

tetroxide for 2 hours, dehydrated in increasing concentrations of ethanol (from $30 \%, 40 \%, 50 \%, 60 \%, 70 \%, 80 \%$, $90 \%, 95 \%$ to $100 \%)$ and were critical-point-dried. The scaffolds were coated with gold (Sputter Coater-SPI Supplies) for $90 \mathrm{~s}$ at $13 \mathrm{~mA}$. Images were taken in the Department of Metallurgy and Materials Engineering, Federal University of Minas Gerais, Brazil, using the scanning electronic microscope (JEOL $6360 \mathrm{LV}$ ), at $15 \mathrm{kV}$ and $750 \mathrm{~mA}$.

2.12. Statistical Analysis. The results were analyzed using Prism 4.0 software, and the chosen method was a one-way ANOVA test and a Bonferroni's posttest.

\section{Results and Discussion}

Considering that cellular viability and secretion capability are the first parameters used to evaluate the cytotoxicity of a given material, we performed the MTT assay, which allows the analysis of viability as well as, indirectly, the cellular proliferation. We cultured the osteoblasts in the presence of the different biomaterial powders. The cellular viability was measured and compared to control osteoblasts cultured in pure medium. The results showed that the viability of osteoblasts incubated in the presence of $0.25 \%$ LiHA was similar to control or commercial HA in all sintering temperatures (Figure $1(\mathrm{a})$ ). When using $0.50 \% \mathrm{LiHA}$, osteoblasts viability was enhanced mainly at $900^{\circ} \mathrm{C}, 1000^{\circ} \mathrm{C}$, and $1300^{\circ} \mathrm{C}$ (Figure 1(b)). $1.0 \%$ LiHA caused a significant enhancement in osteoblast viability at all sintering temperatures compared to the control or commercial HA (Figure 1(c)), and 2.0\% LiHA did not interfere with osteoblast viability (Figure 1(d)). The results showed that the 0.5 and $1.0 \%$ concentrations led to an increase in osteoblast viability suggesting proliferation enhancement. This finding is in accord with a previous study [18] which showed that Li enhanced the bioactivity of calcium composite cements. The alkaline phosphatase activity is an important osteoblast differentiation marker [19]. We evaluated the ALP production of the osteoblasts and the culture supernatant because the osteoblasts produce the enzyme and extrude it to the extracellular medium (Figures 2(a) and 2(b)). The ALP measurements were similar to the control in all tested samples, comparing the cellular and the supernatant results. However, taking in account that the cellular proliferation was enhanced by 0.5 and $1.0 \%$ LiHA, we can affirm that at these concentrations the ALP activity had a discrete impairment. Other authors have shown that biomaterial solubility can alter the behavior of cells cultured in the presence of these biomaterials [20-23]. Because the addition 


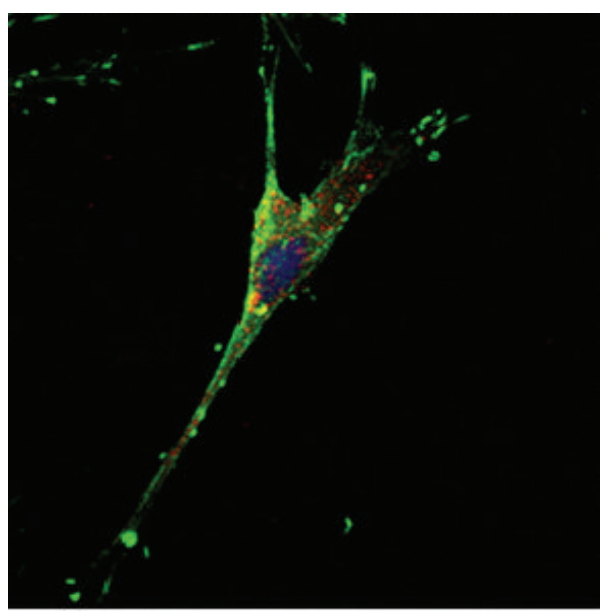

(a)

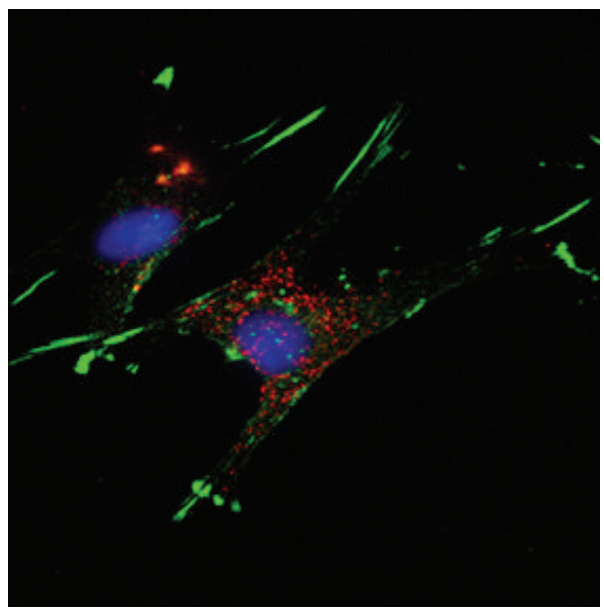

(c)

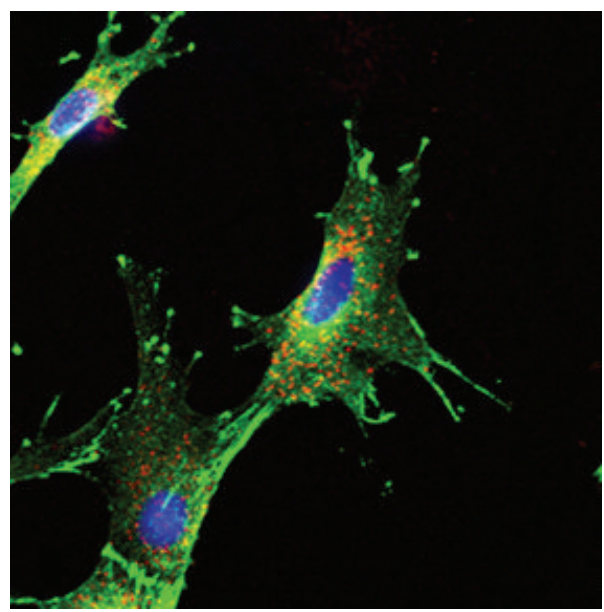

(b)

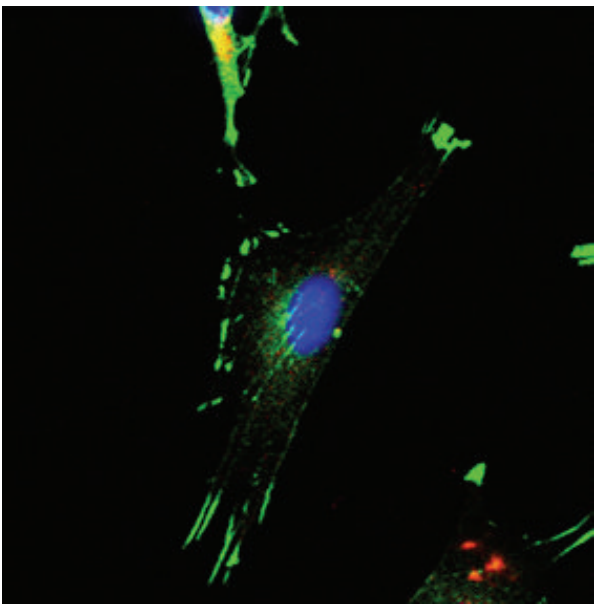

(d)

FIGURE 5: Actin and Vinculin expression of osteoblasts in the presence of LiHA. Magnification 1000x. (a) $0.25 \% \mathrm{LiHA}$ at $900^{\circ} \mathrm{C},(\mathrm{b}) 0.25 \%$ LiHA at $1300^{\circ} \mathrm{C}$, (c) $2.00 \% \mathrm{LiHA}$ at $900^{\circ} \mathrm{C}$, and (d) $2.00 \% \mathrm{LiHA} 1300^{\circ} \mathrm{C}$.

of Li alters the solubility of the samples [9], the observed impairment can be explained by this characteristic. It is important to emphasize that it was a discrete impairment and not an inhibition. The other important aspect to be evaluated is the cellular collagen production, which denotes cellular efficiency [24]. When we measured the collagen production, we found a great decrease when the cells were cultured in the presence of $0.5 \%$ Li samples (Figure 3 ). Although the $1.0 \%$ Li sample did not show the same decrease, we can speculate that it was also caused by the difference in solubility rate. Further investigations are necessary to explain this finding.

Li has been proposed for use as an addictive to ceramic composites [25], but its cytotoxicity is not yet well defined. It has been demonstrated that $\mathrm{Li}$ has a significant effect on blood cell physiology [26]. So we decided to investigate if the ionic product from the dissolution of the LiHA powders would also lead to different responses in osteoblast physiology. We chose to investigate the effects of the highest $(2.0 \%)$ and the lowest $(0.25 \%) \mathrm{Li}$ concentrations and the lowest $\left(900^{\circ} \mathrm{C}\right)$, the median $\left(1100^{\circ} \mathrm{C}\right)$, and the highest $\left(1300^{\circ} \mathrm{C}\right)$ sintering temperatures. We also prepared the ionic product from the dissolution of commercial HA. To evaluate the cellular death rate we used a subdiploid DNA marker, Propidium iodide, and analyzed the marked cells by flow cytometry (Figure 4). Figures 4(a), 4(b), and 4(c) show demonstrative histograms of control cells, commercial HA and LiHA, respectively, and the histograms are similar. Figure 4(d) summarizes the results. These results indicated that all tested samples showed a cell death rate inferior to $10 \%$, which is comparable to viable cultures [27].

It is known that Lithium alters the signaling and differentiation of central nervous system cells [28]. Considering that in osteoblasts, adhesion and differences in morphology are directly related to differentiation, we decided to analyze the influence of the ionic products from LiHA dissolution on the expression of vinculin (a focal adhesion protein) and actin (a cytoskeleton protein). Under confocal microscopy, in all concentrations tested, visualization of the cells revealed a great number of focal adhesions and good cytoskeletal organization indicating that the products from the dissolution of the samples did not alter the proper expression of actin 

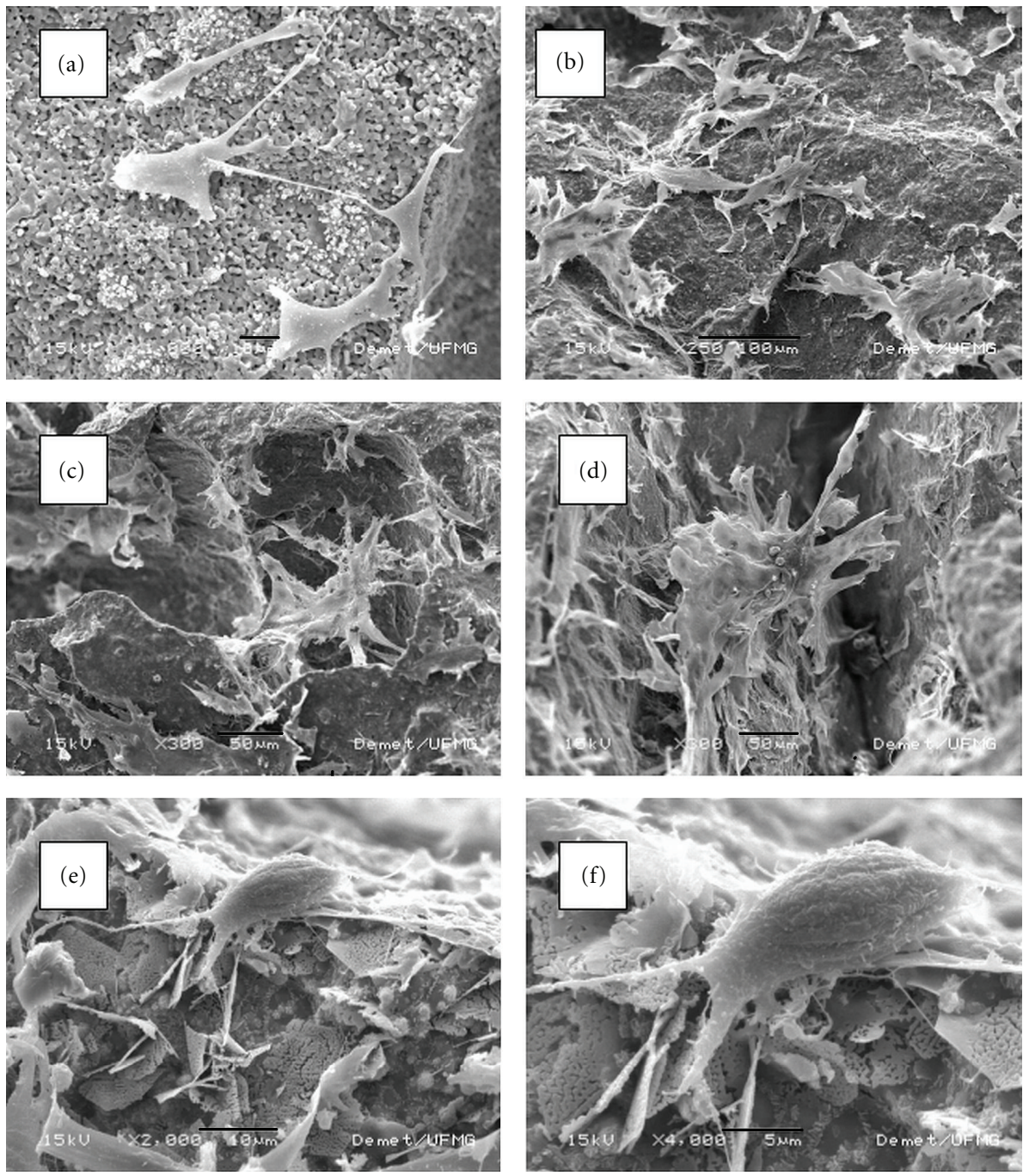

FIGURE 6: SEM micrographs of the morphology of osteoblast cultured on LiHA matrix for 120 hours. Images demonstrated osteoblast adhesion to the matrix surface and interaction between cells. (a) Scale bar: $10 \mu \mathrm{m}$, (b) scale bar: $100 \mu \mathrm{m}$, (c-d) scale bar: $50 \mu \mathrm{m}$, (e) scale bar: $10 \mu \mathrm{m}$, and (f) scale bar: $5 \mu \mathrm{m}$.

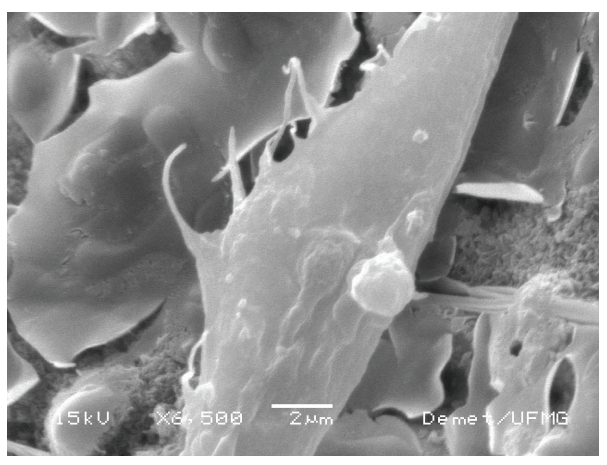

(a)

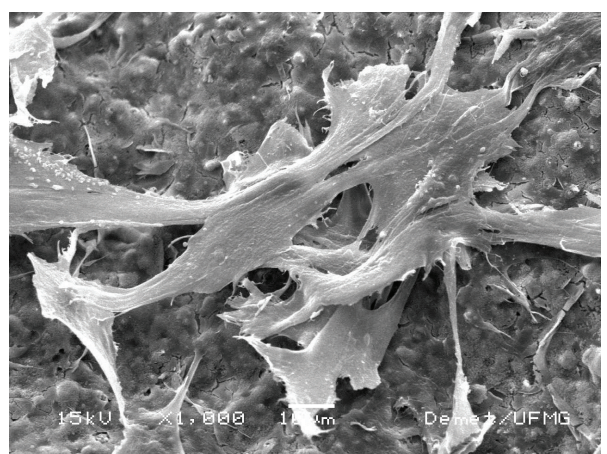

(b)

FIGURE 7: SEM micrographs of the morphology of osteoblast cultured on LiHA matrix for 120 hours. (a) Detail of cell surface showing secretion vesicles indicating normal physiology. Cells are flattened and elongated. Scale bar: $2 \mu \mathrm{m}$. (b) Group of osteoblasts showing a flattened cellular body and a high degree of interconnection. Scale bar: $10 \mu \mathrm{m}$. 


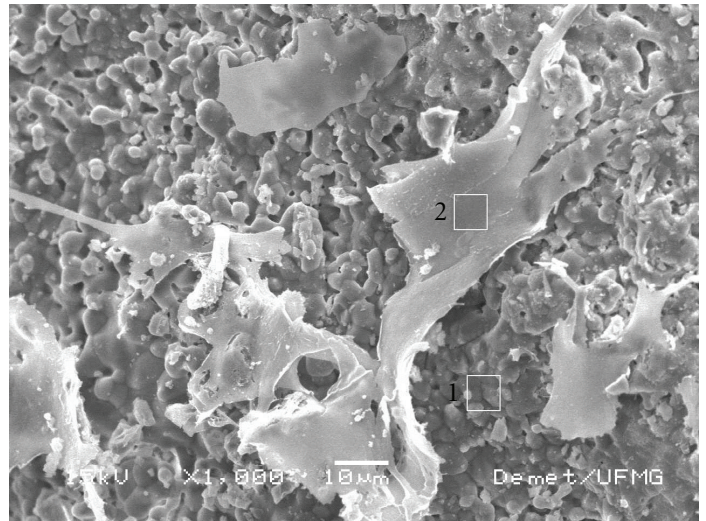

(a)

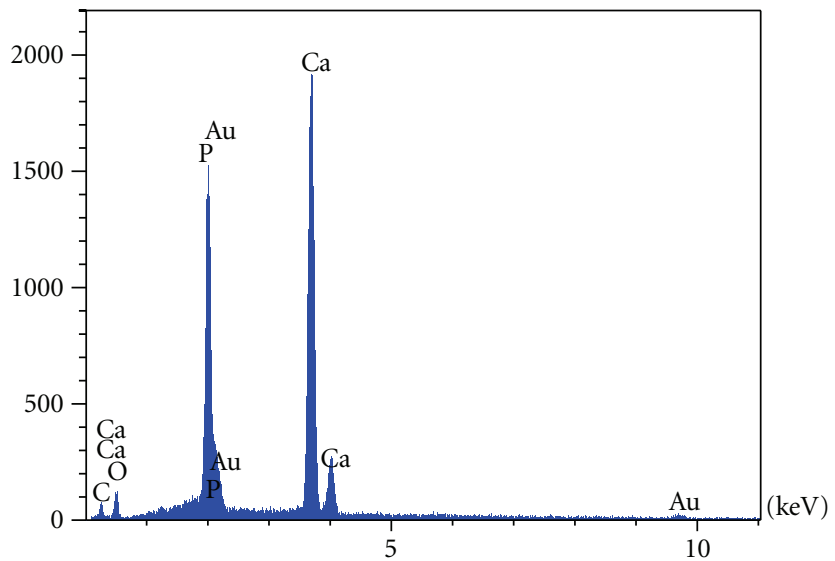

(b)

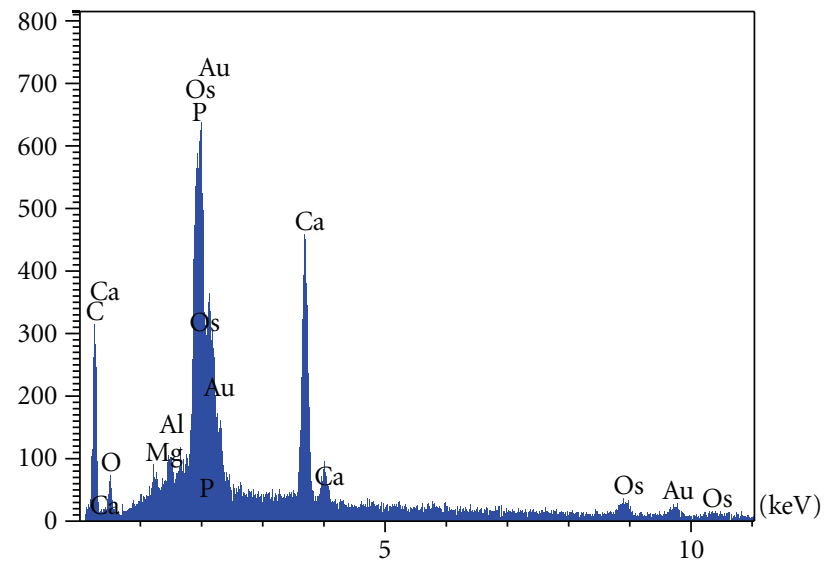

(c)

FIGURE 8: EDS analysis of osteoblast cultured on LiHA matrix for 120 hours. (a) Selected site for EDS analysis. Scale bar: $10 \mu \mathrm{m} .1$ : Analysis performed on the LiHA surface. 2: Analysis performed on the osteoblast surface.

and vinculin (Figure 5). Previous studies have demonstrated that some ions can be added to composites without causing damage to osteoblast adhesion and elongation properties [29-31]. Our findings support that lithium, used in the tested concentrations, also does not interfere with the same properties.
During all the tests, the morphology of the cells was observed under light microscopy. No alteration was observed. However, considering the difference of porosity in the samples sintered at different temperatures, and knowing that this difference can alter cell morphology, we decided to investigate, using electronic microscopy, the osteoblast adhesion and filopodia emission when osteoblasts were cultured on the LiHA sample surface. We used two time points, 72 hours and 120 hours after incubation with LiHa. Naturally the cell density at 120 hours of culture was higher, and the demonstrative images shown here were chosen from this time point. However, in both time points we had good results. The osteoblasts adhered to all porous samples, spread, and showed normal elongation and interconnections between cells. Figures 6 and 7 show demonstrative images that indicate that osteoblasts were able to adhere to the LiHA surface and also interact with other cells and produce secretion vesicles. The EDS analysis confirmed the presence of calcium on the surface of the osteoblasts indicating the normal physiology of these cells (Figure 8).

\section{Conclusion}

The results of this study indicate that the LiHA ceramics are biocompatible and have variable bioactivities, which can be tailored by different combinations of the concentration of lithium carbonate and the sintering temperature. Our findings suggest that LiHA $0.25 \% \mathrm{wt}$, sintered at $1300^{\circ} \mathrm{C}$, combines the necessary physical and structural qualities with favorable biocompatibility characteristics, achieving a bioactivity that seems to be adequate for use as a bone implant material. However, we propose that in vivo experiments should be conducted to validate its use.

\section{Acknowledgments}

This study was partly carried out with the financial support of the Turkish Republic Government Planning Organization in the framework of the Project "Manufacturing and Characterization of Electro-Conductive Bioceramics" (no. 2003 K120810). Dr. F. N. Oktar acknowledges the support of the Portuguese Science and Technology Foundation (FCT Fundaçao para a Ciência e a Tecnologia) under the program "Compromisso com a Ciência," Reference C2008UA/TEMA/01. Financial support of biological studies was provided by CNPq (Brazil), CAPES (Brazil), and FAPEMIG (Brazil). The authors also acknowledge the kind scientific support of Dr. Gultekin Goller from Istanbul Technical University, Turkey and Dr. M. A. Valente from Physic Department of Aveiro University, Portugal.

\section{References}

[1] A. L. Boskey, E. Donnelly, and J. G. Kinnett, "Bone quality: from bench to bedside: opening editorial comment," Clinical Orthopaedics and Related Research, vol. 469, no. 8, pp. 20872089, 2011.

[2] L. L. Hench, "Future developments and applications of biomaterials: an overview," Biomaterials Medical Devices and Artificial Organs, vol. 7, no. 2, pp. 339-350, 1979. 
[3] R. S. Langer and J. P. Vacanti, "Tissue engineering: the challenges ahead," Scientific American, vol. 280, no. 4, pp. 86-89, 1999.

[4] R. Z. LeGeros, "Calcium phosphate-based osteoinductive materials," Chemical Reviews, vol. 108, no. 11, pp. 4742-4753, 2008.

[5] R. Z. Legeros, S. Lin, R. Rohanizadeh, D. Mijares, and J. P. Legeros, "Biphasic calcium phosphate bioceramics: preparation, properties and applications," Journal of Materials Science, vol. 14, no. 3, pp. 201-209, 2003.

[6] S. H. Oh, S. Y. Choi, Y. K. Lee, K. N. Kim, and S. H. Choi, "Effects of lithium fluoride and maleic acid on the bioactivity of calcium aluminate cement: formation of hydroxyapatite in simulated body fluid," Journal of Biomedical Materials Research Part A, vol. 67, no. 1, pp. 104-111, 2003.

[7] J. Wang, K. de Groot, C. van Blitterswijk, and J. de Boer, "Electrolytic deposition of lithium into calcium phosphate coatings," Dental Materials, vol. 25, no. 3, pp. 353-359, 2009.

[8] M. A. Fanovich, M. S. Castro, and J. M. Porto López, "Analysis of the microstructural evolution in hydroxyapatite ceramics by electrical characterisation," Ceramics International, vol. 25, no. 6, pp. 517-522, 1999.

[9] F. N. Oktar, M. R. Demirer, O. Gunduz et al., "Sintering effect on mechanical properties of composites of bovine hydroxyapatite (BHA) and Li2O," Key Engineering Materials, vol. 309311, pp. 49-52, 2006.

[10] I. Mayer, U. Berger, A. Markitziu, and I. Gedalia, "The uptake of lithium ions by synthetic carbonated hydroxyapatite," Calcified Tissue International, vol. 38, no. 5, pp. 293-295, 1986.

[11] F. N. Oktar, K. Kesenci, and E. Pişkin, "Characterization of processed tooth hydroxyapatite for potential biomedical implant applications," Artificial Cells, Blood Substitutes, and Immobilization Biotechnology, vol. 27, no. 4, pp. 367-379, 1999.

[12] J. E. Gough, I. Notingher, and L. L. Hench, "Osteoblast attachment and mineralized nodule formation on rough and smooth 45S5 bioactive glass monoliths," Journal of Biomedical Materials Research Part A, vol. 68, no. 4, pp. 640-650, 2004.

[13] G. L. Yang, F. M. He, X. F. Yang, X. X. Wang, and S. F. Zhao, "In vivo evaluation of bone-bonding ability of RGD-coated porous implant using layer-by-layer electrostatic self-assembly," Journal of Biomedical Materials Research Part A, vol. 90, no. 1, pp. 175-185, 2009.

[14] J. Zhou, L.-G. Ming, B.-F. Ge et al., "Effects of $50 \mathrm{~Hz}$ sinusoidal electromagnetic fields of different intensities on proliferation, differentiation and mineralization potentials of rat osteoblasts," Bone, vol. 49, no. 4, pp. 753-761, 2011.

[15] N. Aydin and M. Bezer, "The effect of an intramedullary implant with a static magnetic field on the healing of the osteotomised rabbit femur," International Orthopaedics, vol. 35, no. 1, pp. 135-141, 2011.

[16] A. Abdelrahim, H. R. Hassanein, and M. Dahaba, "Effect of pulsed electromagnetic field on healing of mandibular fracture: a preliminary clinical study," Journal of Oral and Maxillofacial Surgery, vol. 69, no. 6, pp. 1708-1717, 2011.

[17] P. Valerio, M. M. Pereira, A. M. Goes, and M. F. Leite, "Effects of extracellular calcium concentration on the glutamate release by bioactive glass (BG60S) preincubated osteoblasts," Biomedical Materials, vol. 4, no. 4, Article ID 045011, 2009.

[18] S. H. Oh, S. Y. Choi, S. H. Choi, Y. K. Lee, and K. N. Kim, "The influence of lithium fluoride on in vitro biocompatibility and bioactivity of calcium aluminate-PMMA composite cement," Journal of Materials Science, vol. 15, no. 1, pp. 25-33, 2004.

[19] D. Masquelier, B. Herbert, N. Hauser, P. Mermillod, E. Schonne, and C. Remacle, "Morphologic characterization of osteoblast-like cell cultures isolated from newborn rat calvaria," Calcified Tissue International, vol. 47, no. 2, pp. 92-104, 1990.

[20] H. M. Kim, T. Himeno, M. Kawashita, T. Kokubo, and T. Nakamura, "The mechanism of biomineralization of bonelike apatite on synthetic hydroxyapatite: an in vitro assessment," Journal of the Royal Society Interface, vol. 1, no. 1, pp. 17-22, 2004.

[21] T. R. Arnett, "Acidosis, hypoxia and bone," Archives of Biochemistry and Biophysics, vol. 503, no. 1, pp. 103-109, 2010.

[22] A. Brandao-Burch, J. C. Utting, I. R. Orriss, and T. R. Arnett, "Acidosis inhibits bone formation by osteoblasts In Vitro by preventing mineralization," Calcified Tissue International, vol. 77, no. 3, pp. 167-174, 2005.

[23] S. A. Oh, G. S. Lee, J. H. Park, and H. W. Kim, "Osteoclastic cell behaviors affected by the $\alpha$-tricalcium phosphate based bone cements," Journal of Materials Science, vol. 21, no. 11, pp. 3019-3027, 2010.

[24] T. Elsdale and J. Bard, "Collagen substrata for studies on cell behavior," Journal of Cell Biology, vol. 54, no. 3, pp. 626-637, 1972.

[25] H. Fu, M. N. Rahaman, D. E. Day, and W. Huang, "Effect of pyrophosphate ions on the conversion of calcium-lithiumborate glass to hydroxyapatite in aqueous phosphate solution," Journal of Materials Science, vol. 21, no. 10, pp. 2733-2741, 2010.

[26] D. Focosi, A. Azzarà, R. E. Kast, G. Carulli, and M. Petrini, "Lithium and hematology: established and proposed uses," Journal of Leukocyte Biology, vol. 85, no. 1, pp. 20-28, 2009.

[27] C. Nicoletti, C. Borghesi-Nicoletti, X. Yang, D. H. Schulze, and J. Cerny, "Repertoire diversity of antibody response to bacterial antigens in aged mice. II. Phosphorylcholine-antibody in young and aged mice differ in both $\mathrm{V}(\mathrm{H}) / \mathrm{V}(\mathrm{L})$ gene repertoire and in specificity," Journal of Immunology, vol. 147, no. 8, pp. 2750-2755, 1991.

[28] A. Shaldubina, G. Agam, and R. H. Belmaker, "The mechanism of lithium action: state of the art, ten years later," Progress in Neuro-Psychopharmacology and Biological Psychiatry, vol. 25, no. 4, pp. 855-866, 2001.

[29] W. Paul and C. P. Sharma, "Effect of calcium, zinc and magnesium on the attachment and spreading of osteoblast like cells onto ceramic matrices," Journal of Materials Science, vol. 18, no. 5, pp. 699-703, 2007.

[30] M. S. Sader, R. Z. Legeros, and G. A. Soares, "Human osteoblasts adhesion and proliferation on magnesium-substituted tricalcium phosphate dense tablets," Journal of Materials Science, vol. 20, no. 2, pp. 521-527, 2009.

[31] Y. Yamasaki, Y. Yoshida, M. Okazaki et al., "Action of FGMgCO3Ap-collagen composite in promoting bone formation," Biomaterials, vol. 24, no. 27, pp. 4913-4920, 2003. 

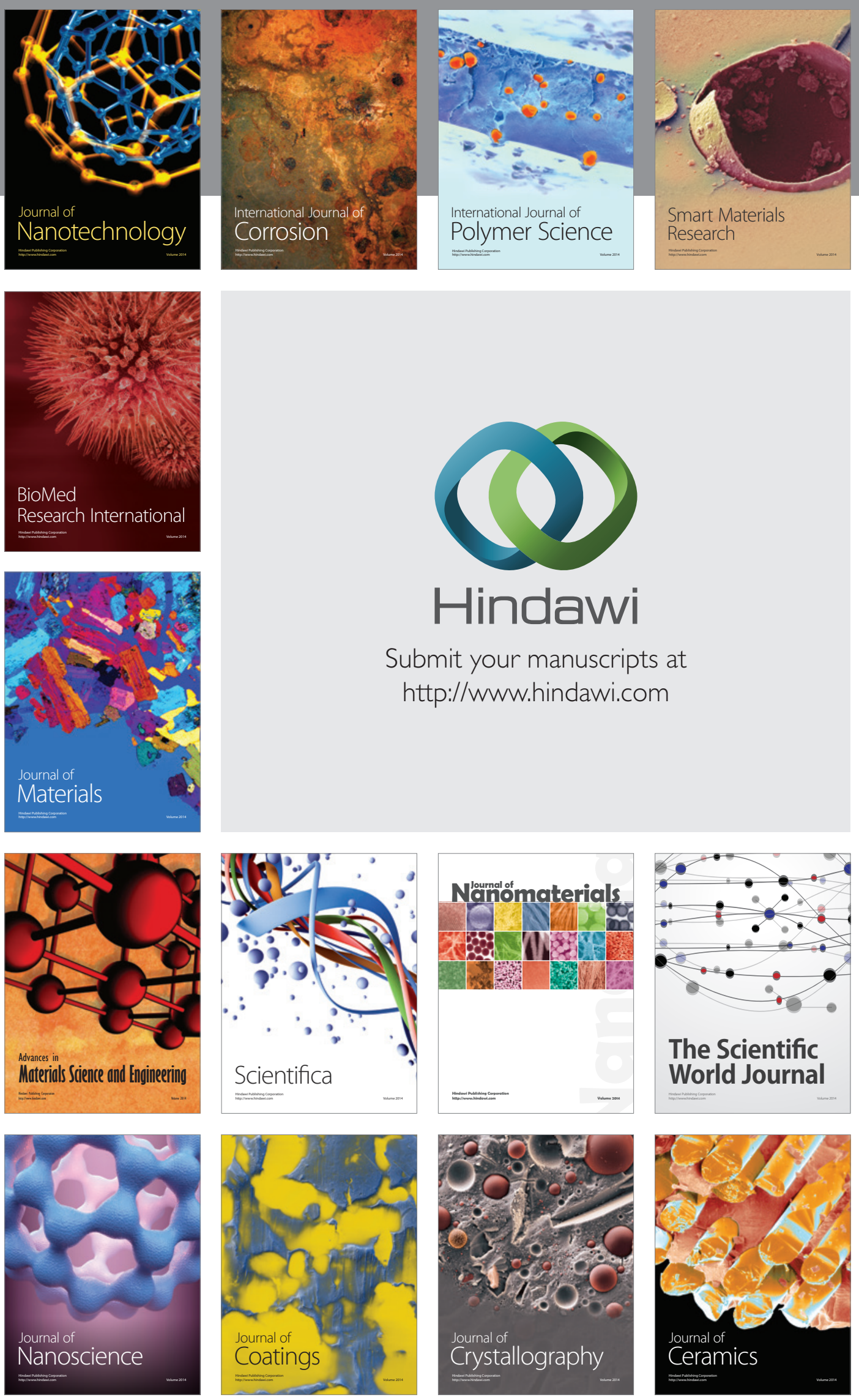

The Scientific World Journal

Submit your manuscripts at

http://www.hindawi.com

\section{World Journal}

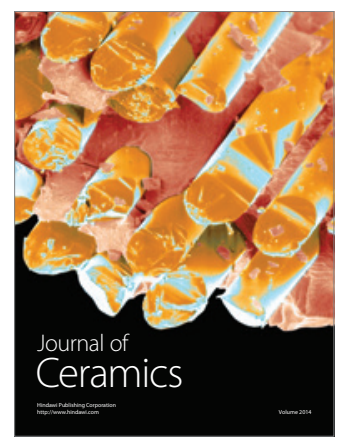

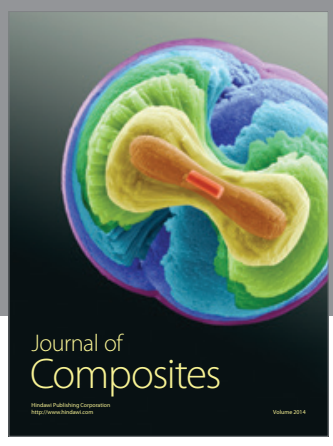
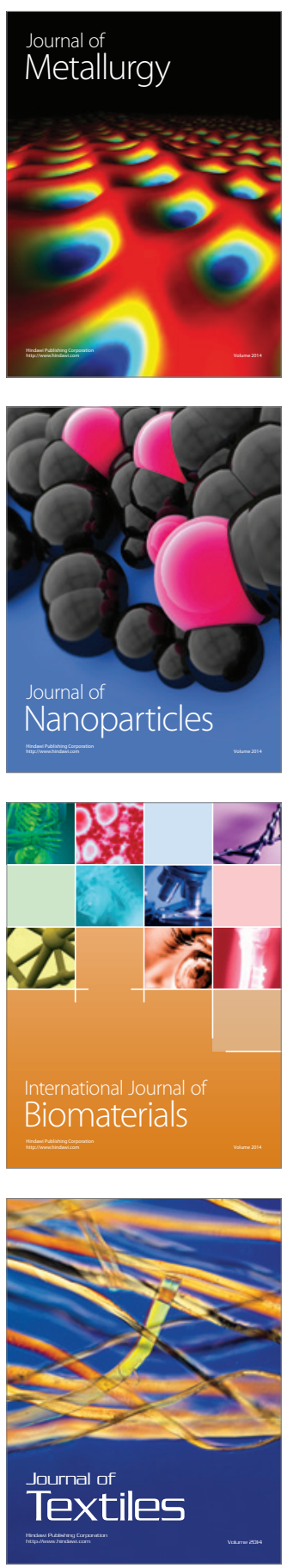